\title{
MENGEMBANGKAN WIRAUSAHA PENDIDIKAN PRIVAT BAHASA ASING
}

\author{
Retno Dwi Wijayanti \\ Program Studi Pendidikan Guru Sekolah Dasar \\ Fakultas Keguruan dan Ilmu Pendidikan \\ Universitas Nahdlatul Ulama Sidoarjo \\ Email: retnodwi84100@gmail.com
}

\section{Pengantar}

Entrepreuner adalah seorang manusia yang mempunyai daya semangat juang yang tinggi, ulet, ide yang brilian, pantang menyerah dalam menghadapi rintangan apapun yang dapat menciptakan lapangan kerja yang berguna untuk kepentingan bersama-sama dan mengurangi jumlah pengangguran yang ada disekitarnya demi kesejahteraan dan kemakmuran hidup. (Klein, 2008)

Sedangkan Edupreneur atau educational entrepreneur berasal dari dua kata yaitu education yang bermakna pendidikan dan entrepreneur bermakna pengusaha atau wirausahawan. Ada juga yang menyamakan istilah edupreneur dengan istilah istilah techerpreuner. di indonesia sangat sedikit yang menjadi entrepreneur dikarenakan pola pikir orang indonesia yang masih berpikir bahwa setelah mengenyam pendidikan masih bergantung menj adi karyawan atau pegawai negeri tidak banyak yang berpikir untuk menciptakan lapangan kerja. Lalu lapangan kerja di Indonesia tidak sebanding dengan pencari kerja yang notabennya kebanyakan berpendidikan. Karena itu masih banyaknya pengangguran yang berpendidikan dan bertitel sarjana muda penggaguran. Karena penyebab tersebut jumlah entrepeuneur di Indonesia baru mencapai $1,65 \%$ dari total populasi penduduk Indonesia dan target standart untuk perekonomian bosa dikatakan maju minimal membutuhkan $2 \%$ pelaku entrepreneur dari populasi penduduk suatu negara. (Purnomo, 2017)

Maka dari itu seorang entrepreneur harus cerdas, berani dan memiliki insting dalam mengambil keputusan dalam melakukan usaha supaya bisa berjalan dengan lancar. Seorang entrepreneur sebenarnya juga bisa memulai bisnis tanpa modal tetapi bisa dengan menggunakan skill yang kita miliki . 
dengan skiil tersebut, kita bisa menggerahkan kemampuan tersebut yang bisa menjadi modal untuk membuka bisnis seperti privat bahasa asing salah satunya. Sebagai langkah awal para entrepreneur juga harus pandai dalam membaca peluang yang ada, supaya tidak bergantung dengan program lapangan pekerjaan yang dinsediakan di Indonesia. Juga dengan memperbanyak rekan atau relasi agar mempermudah dalam menjalankan bisnis yang akan direncanakan tersebut.

Salah satu bisnis yang di awali modal yang sedikit tetapi dengan skill yaitu berbisnis dalam bimbingan belajar.banyaknya bimbingan belajar yang sudah menjamur di Indonesia, membuat seorsng entrepreneur harus berpikir keras dengan menciptakan ide yang brilian dalam berbisnis bimbingan belajar. Supaya bisa menarik minat masyarakat atau khalayak umum. Juga dengan metode belajar yang kreatif atau berbeda dengan metode belajar yang sudah umum agar lebih menyenangkan dan para pembelajar pun puas dengan pelayanan dari pengajar. Bimbingan belajar yang bisa diterapkan untuk menjadi peluang usaha yaitu membu ka

bimbingan Belajar Bahasa Asing. dengan membuka Bimbingan Belajar Bahasa Asin $\mathrm{g}$ bisa

menciptakan lapangan kerja bagi para pengajar atau mahasiswa yang magang untu $\mathrm{k}$ mengajar di bimbingan belajar bahasa asing tersebut. (Dena, 2017)

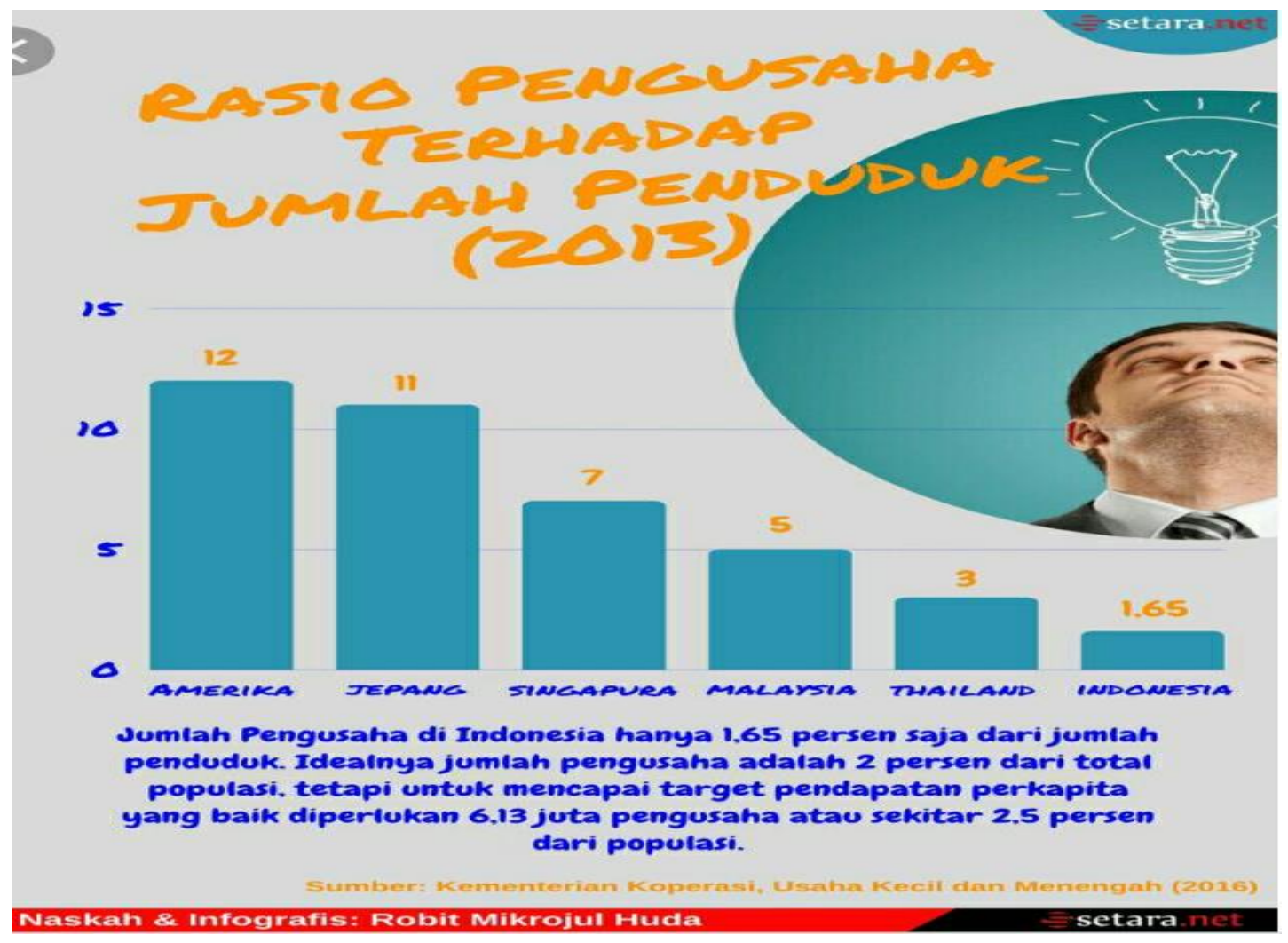


Gambar 1. Infografik rasio pengusaha terhadap jumlah penduduk (kementerian koperasi, usaha kecil dan menengah, 2016

\section{Alasan Menjadi Seorang Entrepeuner}

Alasan pertama menjadi seorang entrepeuner adalah bagaimana kita menciptakan lapanggan perkerjaan minimal untuk diri sendiri. Lebih bagus dan baik lagi apabila seorang entrepeuner menciptakan kapangan pekerjaan untuk masyarakat umum, seperti yang sudah kita ketahui bahwa untuk bisa dikatakan sesuai standar untuk perekonomian menjadi maju minimal membutuhkan $2 \%$ entrepeuner di dalam suatu negara. Alasan kedua menjadi entrepeuner adalah lebih banyak waktu luang untuk melakukan kegiatan lain sehingga banyak kegiatan yang bisa kita lakukan selain menjadi entrepeuner, seorang entrepeuner yang hebat dalam pendidikan dia dapat memajukan sistem pendidikan di negaranya.Selain alsan di atas alasan menjadi entrepeuner adaalah lebih banyaknya penghasilan yang kita dapat dari hasil usaha atau bisnis yang kita ciptakan.

\section{Hal-hal yang dilakukan agar usaha berkembang}

Setelah bisnis berkembang, bukan berarti akan bisa berjalan secara otomatis atau autopilot. Perlu rencana matang agar bisa bertahan menghadapi persaingan serta terus mempertahankan grafik pertumbuhannya. Sebagai pemilik bisnis, jika sudah berjalan, cukup melakukan monitoring dengan memikirkan perkembangan bisnis sesuai dengan target yang ingin dicapai. Memiliki mimpi dan keinginaan yang kuat. Para pebisnis besar sejak mula telah punya mimpi untuk bisnis yang ditekuni. Mereka enggan untuk biasa-biasa saja dalam menjalankan bisnisnya. Mereka sadar bahwa siapa saja boleh punya mimpi dan mimpi itu gratis. Tidak ada ruang untuk memiliki pola pikir yang sempit seperti, "Saya cukup segini dulu,". Anda harus terus bergerak maju jika ingin berada di puncak.

Pemasaran adalah ujung tombak perusahaan. Cara pemasaran dan strategi pemasaran jitu menjadikan pertumbuhan perusahaan tetap terjaga. Kenali dan gunakan teknologi untuk usaha yang akan dijalankan. Jangan sampai menjadi orang yang gaptek (gagap teknologi). Kenali dan pelajari bagaimana teknologi bisa membantu bisnis Anda terus bertumbuh. Mau belajar adalah kunci sukses seseorang. Ingat, teknologi bisa saja menjadi hambatan bagi bisnis sekaligus senjata untuk pertumbuhan bisnis. Ikuti perkembaangan zaman, mengikuti tren bisnis yang sedang berkembang adalah hal yang harus dikenali secara matang. Jangan sampai terjadi istilah ketinggalan zaman.

\section{Penutup}


Wirausaha pendidikan adalah salah satu usaha atau bisnis di bidang pendidikan yang sangat menguntungkan bagi para pelaku bisnis dan juga negara. Selain untuk menciptakan lapangan pekerjaan bagi masyarakat maupun diri sendiri wirausaha pendidikan adalah salah satu cara meningkatkan kuwalitas pendidikan. Dengan meningkatnya wirausaha pendidikan dibidang privat bahasa asing diharapkan masyarakat lebih mampu berkompetensi dan bersaing secara baik. Dengan wirausaha pendidikan juga dapat meningkatkan pendapatan individu pelaku bisnis maupun negara karena semakin banyak individu yang berwirausaha maka akan semakin maju perekonomian negaranya.

\section{Refference}

Asitah, N., Usmawati, D.Z., Rosyidah, E., \& Purnomo, A. (2017). MI Hasyim Asy'ari Ilmu Harus Terus Mengarus. In Wirausaha Pendidikan Indonesia (Jilid 2). Sidoarjo: UnusidaPress. (Asitahetal., 2017)

Dena, M. (2017). Membangun Bisnis Usaha Bimbingan Belajar Bahasa Jepang.http://googleweblight.com/i?u=http://www.academia.edu/35768582/MEM BANGUN_BISNIS_USAHA_BIMBINGAN_BELAJAR_BAHASA_JEPANG\& hl=id-ID

Irawan, D. E., Purnomo, A., Sutiksno, D. U., Abraham, J., Alamsyah, A., Saputra, D. H., Tjokorda, J., Rosyidah, E. (2018). Kajian Pendidikan Tinggi IDRI untuk DPR RI dan Ristek Dikti 2018. Bandung: ITB Press. ～～(Irawan etal., 2018)

Purnomo, A. (2017, December 5). Pengertian Edupreneur. http://doi.org/10.17605/OSF.IO/J3BCR (Purnomo, 2017)

Sholichah, S.A., Istiqomah, A., Rosyidah, E., \& Purnomo, A. (2017). MI Darun Najah Berfikir Berkarya Berdzikir. In Wirausaha Pendidikan Indonesia (Jilid 3). Sidoarjo: UnusidaPress. (Sholichah etal., 2017)

Yuniarti, D., Kautsari, M.F., Sholichah, F., Purnomo, A., \& Rosyidah, E. (2017). SMP SMA Al-AminPonpes Bahrul Hidayah Serahkan pada Allah Ta'ala. In Wirausaha Pendidikan Indonesia (Jilid 1). Sidoarjo: UnusidaPress. (Yuniarti etal., 2017) 
